\title{
PRÁCTICAS MORTUORIAS DE CAZADORES-RECOLECTORES TARDÍOS DE LOS DESIERTOS DE ALTURA DEL NOROESTE ARGENTINO: EL FARDO FUNERARIO DE QUEBRADA SECA 3
}

\author{
Lucia G. Gonzalez Baroni* , Salomón Hocsman¹,2 y Carlos A. Aschero ${ }^{1,2}$
}

\begin{abstract}
${ }^{I}$ Instituto de Arqueología y Museo. Facultad de Ciencias Naturales e Instituto Miguel Lillo. Universidad Nacional de Tucumán (FCNeIML, UNT). San Miguel de Tucumán. Argentina

${ }^{2}$ CONICET - Instituto Superior de Estudios Sociales (CONICET-UNT). San Miguel de Tucumán. Argentina
\end{abstract}

PALABRAS CLAVE bioarqueología; feto; entierro secundario; cazadores-recolectores tardíos; Puna argentina

\begin{abstract}
RESUMEN Se presentan el análisis bioarqueológico y las características de un fardo funerario recuperado en el abrigo rocoso Quebrada Seca 3 (Antofagasta de la Sierra, Catamarca, Argentina), con fechados entre 4900 y 4400 años $\mathrm{AP}$, correspondiente a cazadores-recolectores en tránsito a la producción de alimentos. Los objetivos son abordar las características bioarqueológicas del individuo, describir el fardo y su contenido y establecer el tipo de depósito funerario. El fardo es descripto y graficado mediante fotos y dibujos y se incluyen observaciones tafonómicas. Los restos humanos contenidos en el fardo se analizaron para establecer el número mínimo de individuos (NMI), medidas de abundancia taxonómica y relativa, estimación de edad y posible causa de muerte. Para definir el tipo de depósito funerario se con-
\end{abstract}

trastaron datos de campo y características del fardo con bibliografía especializada. El fardo funerario consiste en dos cueros de camélido, uno usado como cobertura externa y otro como envoltorio de los restos óseos humanos. Ambos cueros conforman un "paquete" atado con dos cordeles y rodeado y cubierto por haces de gramíneas. Los restos humanos hallados dentro del fardo arrojaron un NMI de 1, menos del $65 \%$ de representación ósea y una edad estimada de 28 semanas de gestación. La posible causa de muerte de este feto habría sido su inviabilidad por parto prematuro. El depósito funerario es de tipo secundario en el que la manipulación antrópica está referida únicamente a la desarticulación del esqueleto al ser colocado en el fardo. Rev Arg Antrop Biol 19(1), 2017. doi:10.17139/raab.2017.0019.01.10

KEY WORDS bioarchaeology; fetus; secondary burial; late hunter-gatherers; Argentinian Puna

ABSTRACT In this paper we present the bioarchaeological analysis and characterization of a funerary bundle found at Quebrada Seca 3 rock shelter (Antofagasta de la Sierra, Catamarca, Argentina) that corresponds to the transition from hunting and gathering to food production, ca. 4900 and 4400 years BP. The goals of this paper are to address the bioarchaeological characteristics of this individual, to describe the bundle and its contents, and to identify the type of funeral deposit. The bundle is described and represented by means of pictures and drawings, and taphonomic observations are included. The human remains in the funerary bundle are analyzed to establish the minimum number of individuals (MNI), the taxonomic and relative abundance of skeletal remains, age estimate and possible cause of death. In order to define the type of funerary deposit, both the field data and the characteristics of the bundle were assessed following specialized bibliography. The funerary bundle consists of two camelid hides, one of them used as an outer covering, and the other as a wrapper for the human skeletal remains. Both leather pieces form a "package" tied with two pieces of cord and covered with grass bundles. The human remains found inside the bundle showed a MNI equal to 1 , a skeletal integrity of less than $65 \%$ of bone representation, and an estimated age of about 28 weeks of gestation. The possible cause of death of the fetus would have been its unlikelihood to survive due to its premature birth. The funeral deposit is of a secondary type, with anthropic manipulation referring only to the disarticulation of the skeleton when placed in the bundle. Rev Arg Antrop Biol 19(1), 2017. doi:10.17139/raab.2017.0019.01.10
Las evidencias de enterratorios correspondientes a cazadores-recolectores son realmente escasas en las porciones altas de los Andes Centro-Sur. Se analiza aquí el fardo funerario y los restos bioarqueológicos pertenecientes a un entierro recuperado en la capa $2 b(2)$ del sitio arqueológico Quebrada Seca 3, localizado en Antofagasta de la Sierra (Catamarca, Argentina). Las fechas obtenidas, entre 4900 y 4400 años AP, corresponden a ocupaciones de cazadores-recolectores en tránsito a la producción de alimentos.

El abordaje de este hallazgo permite una aproximación a las prácticas funerarias de los cazadores-recolectores finales de la región pu-

\footnotetext{
*Correspondencia a: Lucia G. Gonzalez Baroni. Instituto de Arqueología y Museo. Facultad de Ciencias Naturales e Instituto Miguel Lillo. Universidad Nacional de Tucumán. San Martín 1545. San Miguel de Tucumán 4000. Tucumán. Argentina. E-mail: luciagonzalezbaroni@gmail.com
}

Financiamiento: Proyectos PIP 464 y PIUNT G503 (C. Aschero). PICT 1703 (S. Hocsman).

Recibido 17 Mayo 2015; aceptado 2 Marzo 2016

doi:10.17139/raab.2017.0019.01.10 
neña meridional de los Andes Centro-Sur en relación con 3 elementos: 1) el tratamiento de los infantes, 2) las características y composición de los fardos funerarios y de los ajuares y 3) la sustracción y transporte de partes.

Por otra parte, debe considerarse que el hallazgo de fetos y perinatos, como es este el caso, no es frecuente en los contextos arqueológicos debido a su fragilidad y a los efectos de múltiples procesos postdepositacionales que pueden deteriorar este sensible registro, así como a una inadecuada metodología de excavación y al desconocimiento de los arqueólogos de la anatomía ósea inmadura (García Mancuso, 2008). Asimismo, los estudios de índole bioarqueológica también son escasos (Scheuer y Black, 2000; Luna y Aranda, 2005; García Mancuso, 2008) y no se ha profundizado en los métodos para estimar la edad y el sexo de fetos y perinatos, por la naturaleza de los mismos, como sí se ha hecho para individuos infantiles, juveniles y adultos (González Martín, 1999; Scheuer y Black, 2000). Debido a esto se destaca la combinación de los resultados proporcionados por distintas técnicas visuales con diferentes mediciones óseas en la estimación etaria para incrementar la consistencia de los mismos.

\section{El sitio Quebrada Seca 3}

El sitio Quebrada Seca 3 (QS3) se encuentra ubicado a aproximadamente $15 \mathrm{~km}$ al este de la localidad de Antofagasta de la Sierra, en la provincia de Catamarca (Argentina), en la porción meridional de los Andes Centro-Sur. Ambientalmente forma parte de la Puna Salada, un desierto de altura por encima de los $3500 \mathrm{msnm}$ que se caracteriza por una sequedad extrema. Sus coordenadas geográficas son $67^{\circ} 25^{\prime}$ longitud oeste y $26^{\circ} 5^{\prime}$ latitud sur.

El sitio al que se hace referencia es un abrigo rocoso ubicado al pie del farallón de ignimbritas que conforma la margen sur de la vega de Quebrada Seca. Se encuentra a una altitud de $4100 \mathrm{msnm}$, a una altura media entre la pampa y la vega de Quebrada Seca (Aschero, 1988). La boca del abrigo está orientada hacia el noreste y presenta un área de reparo cuyas dimensiones lineales, en ancho y profundidad desde el área de goteo hasta la pared del fondo, son de $9 \times 5 \mathrm{~m}$, con una superficie promedio de $24 \mathrm{~m}^{2}$ (Fig. 1). Dicha área fue dividida en un espacio exterior y uno interior, designados alero y cueva respectivamente, por la existencia de una visera rocosa interna que restringe el espacio útil de habitación (Aschero et al., 1991) (Fig. 2).

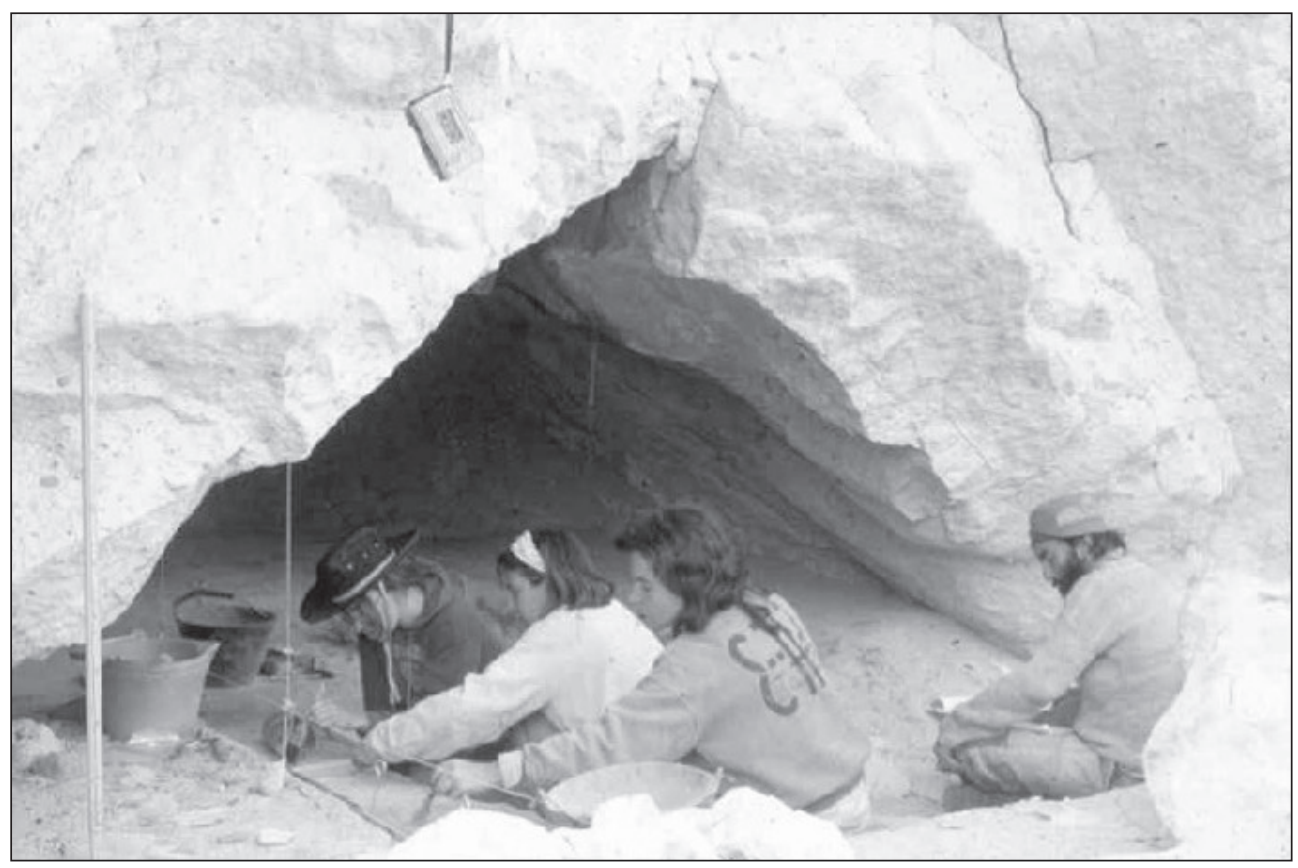

Fig.1. Excavaciones en Quebrada Seca 3. Principios de la década del '80. 


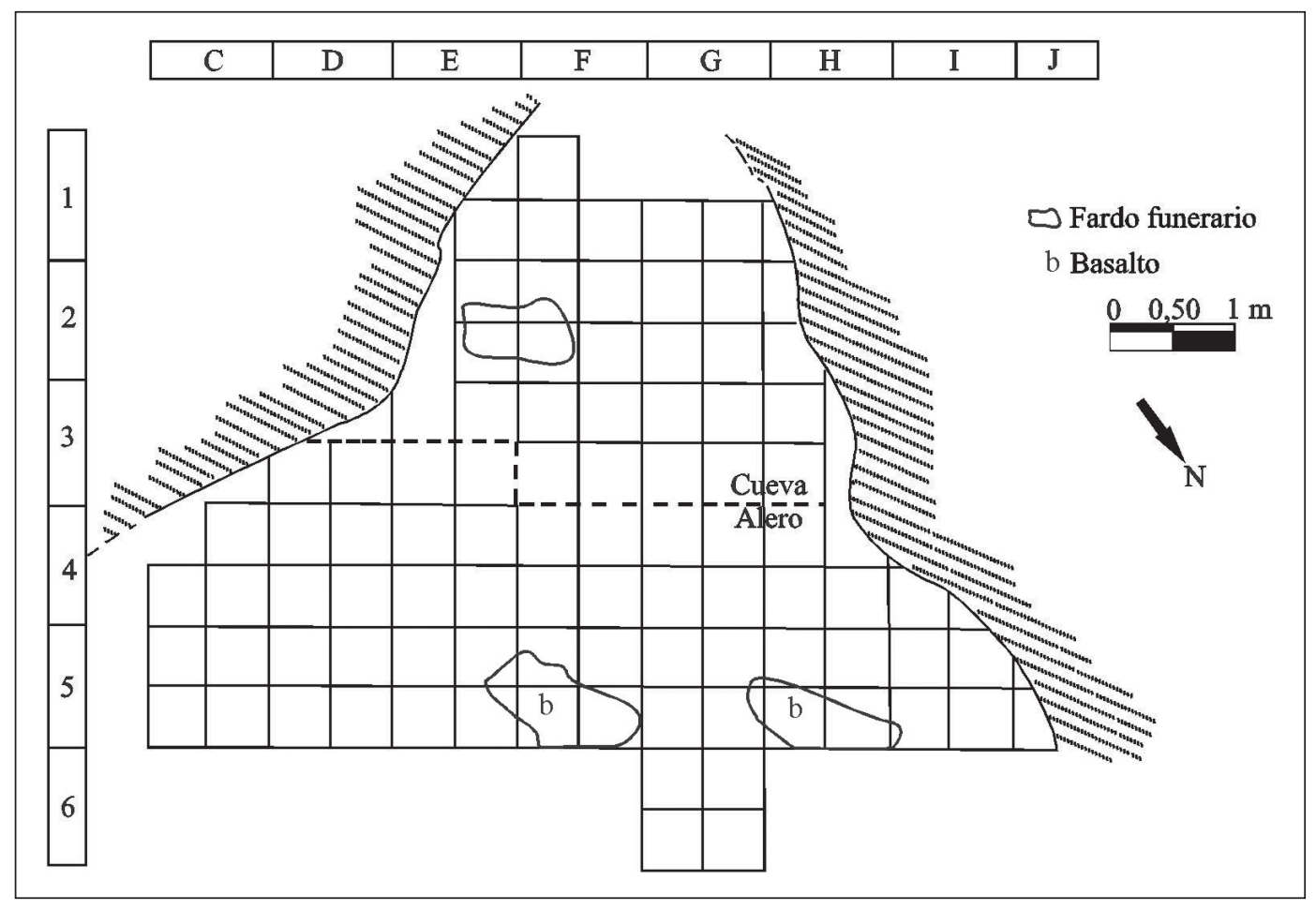

Fig. 2. Ubicación del fardo funerario en el nivel 2 b2 del sitio Quebrada Seca 3 (modificado de Aschero et al., 1991).

Quebrada Seca 3 se comenzó a excavar en el año 1983 y el fardo objeto de este trabajo se recuperó en 1988. La excavación del sitio se basó en un cuadriculado trazado en cuadros de $1 \mathrm{x}$ $1 \mathrm{~m}$, conformando una grilla alfanumérica (Fig. 2), subdivididos en microsectores de $0,50 \mathrm{~m}$, denominados a, b, c y d (Aschero, 1988). Se trabajó por decapage, siguiendo los agrupamientos o dispersiones de artefactos, ecofactos y estructuras. A cada uno de estos decapages se los denominó "extracciones". Se definieron también "niveles de ocupación", que podían incluir una o más extracciones según la articulación y fisonomía de los vestigios, su superposición y sus profundidades (Aschero, 1988; Aschero et al., 1993-94).

En el inicio de las excavaciones este reparo rocoso estaba totalmente colmatado con sedimento y fue destapándose con el avance de las mismas. Sobre la capa $2 b(2)$ fueron sucesivamente extraídas la capa " 0 " de arena y excrementos de roedores consolidados contra las paredes; la lente 1x, que constituye un episodio de depositación restringido dentro de la capa 0 , compuesto por intercalaciones de restos vege- tales, faunísticos y sedimentos carbonosos, a lo que se suma una cesta decorada y ecofactos diversos; una capa 1 , un sedimento compactado limo-arenoso arqueológicamente estéril; una capa $2 \mathrm{a}$ y otra $2 \mathrm{~b}$, ambas arenosas con diferente granulometría. La capa 2a contenía escasos restos antropógenos y la capa $2 \mathrm{~b}$ estaba constituida por un sedimento areno-limoso en el que la presencia, con densidades diferentes, de aportes antrópicos (espículas de carbón, cenizas, artefactos líticos, astillas óseas y restos vegetales) marcaba diferencias estratigráficas. Estas diferencias, dentro de la matriz relativamente homogénea de la capa $2 b$, permitieron separar las subcapas (1) a (22), que comprenden un lapso de ca.7000 años de presencia humana reiterada en el sitio (Aschero, 1988; Aschero et al., 1991).

Durante el transcurso de las excavaciones el área correspondiente a la cueva se fue ampliando, mostrándose como un espacio útil de habitación en posición sentada a partir del nivel $2 \mathrm{~b} 2 \mathrm{y}$ hasta el $2 \mathrm{~b} 13$, y en posición de pie para los niveles por debajo de 2b14. Consecuentemente, para las ocupaciones primero citadas, que son las que interesan en este trabajo, esa visera interior de- 
bió de ser un elemento condicionante en la utilización del espacio (Aschero et al., 1993-94).

\section{Distribución de vestigios en el nivel $2 b 2$ y posición estratigráfica del fardo funerario}

El nivel 2 b2 corresponde a una ocupación de cazadores-recolectores en tránsito a la producción de alimentos; específicamente, cazadoresrecolectores finales en un momento inicial del proceso de tránsito (Aschero y Hocsman, 2011). El nivel fue definido como una base residencial con espacios acondicionados y equipamiento a partir de evidencias de organización del espacio, de actividades y de descarte/abandono de artefactos líticos y faunísticos, de ubicación de fogones, etc. (Aschero et al., 1991; Aschero et al., 1993-94; Manzi 1994, 2006). Estas evidencias en conjunto permiten sostener que el sitio en este nivel constituyó un locus de uso redundante y estacional por parte de unidades sociales reducidas (Aschero et al., 1993-94). Dicho nivel muestra diversas estructuras de combustión y distintas concentraciones de carbones sin áreas de rubefacción (Aschero et al., 1991). Asociados a estas estructuras se presentan varios conjuntos de restos arqueofaunísticos y de materiales líticos tallados (Aschero et al., 1991; Aschero et al., 1993-94).

Las mayores densidades de materiales arqueofaunísticos se encontraron en el espacio topográfico denominado cueva, específicamente en los sectores contiguos E2 y F2. Esto respondería a criterios organizativos vinculados con el aprovechamiento de la topografía del nivel de ocupación. Así, de acuerdo con Manzi (1994), el espacio libre, de dimensiones muy reducidas, no permitía o imposibilitaba que se lo utilizara para la realización de actividades, por lo que habría sido utilizado como área de evacuación o vaciadero. Ahora bien, con respecto a los materiales líticos tallados, las mayores concentraciones de desechos de talla contrastan con la distribución de los restos faunísticos presentándose espacialmente diferenciadas. Las densidades más altas de desechos líticos se localizan en las áreas de circulación y próximas a los fogones, lo que sugiere que se trata de acumulaciones producto del descarte primario en áreas de actividad (Aschero et al., 1991). Las mayores frecuencias y di- versidad de artefactos se disponen hacia el frente del reparo rocoso, en el sector alero, por ser el espacio habitable, y a la izquierda de los bloques que afloran desde la superficie, que posiblemente condicionaron las actividades (Manzi, 2006). Solo algunas concentraciones limitadas se extienden al sector cueva, donde la depositación sería secundaria, lo que implicaría la remoción de desechos líticos de otras ubicaciones (Aschero et al., 1991; Manzi, 2006).

Se cuenta con tres dataciones radiocarbónicas para este nivel: una proviene de una estructura de combustión localizada en el sector alero (4930 \pm 110 AP - AC 1115 - carbón) y otras dos del enterratorio que es objeto de este trabajo (4510 100 AP - Beta 27801 - gramíneas del fardo funerario y $4410 \pm 60$ AP - UGA 8357 - hueso humano: húmero). Las fechas no están calibradas.

El fardo fue encontrado entre los cuadros E2 y F2, en los microsectores E2b-d y F2a-c, en el nivel $2 \mathrm{~b}(2) 2^{\circ}$ extracción y dentro de la denominada "cueva", a unos $80 \mathrm{~cm}$ de la pared de fondo (para una caracterización en detalle del fardo ver el punto siguiente: "El fardo funerario"). La segunda extracción del nivel referido corresponde a un cambio en el mapeo de los artefactos por la superposición de muchos de ellos en las plantas a escala 1:10. No hay cambios sedimentológicos ni en la densidad de artefactos y, en relación con el fardo funerario, en ese primer decapage aparecieron gran cantidad de astillas óseas, entre otros artefactos y ecofactos, por encima y alrededor de la posición en que iba a aparecer el fardo, los que motivaron el cambio de planta. Esa densidad de ecofactos y artefactos de la primer extracción (predominantemente astillas óseas) se mantuvo sobre y dentro de los haces de paja que contenían el fardo -contra la pared izquierda (este) de la cueva- y alrededor de estos, en un radio de unos $0,60 \mathrm{~m}$. Los vestigios antrópicos, con menor densidad, continuaban en todo el espacio de la cueva, de pared a pared. La distancia entre paredes, transversal a la posición del fardo, era de 2,70 m y la altura del techo en la oquedad variaba entre $0,70 \mathrm{~m}$ (sobre el fardo) a $1,00 \mathrm{~m}$ en el centro, lo cual impedía la posición erguida para un individuo adulto.

Sobre y entre los haces de paja del fardo se recuperaron fragmentos longitudinales y transversales de diáfisis de huesos largos, vertebras 
aisladas y articuladas, molares y fragmentos de costillas, todos ellos de camélidos; también se hallaron abundantes astillas óseas no identificadas y alguna lasca pequeña. En el radio de hasta $0,60 \mathrm{~m}$ del fardo, fuera de la acumulación de gramíneas, se recuperaron unas 40 astillas óseas, fragmentos de vertebras y de diáfisis de huesos largos de camélidos, alguna pluma de ave voladora, 8 lascas pequeñas de vulcanitas locales, una piedra con termo-alteración y ceniza adherida (piedra de fogón), así como carbones aislados.

El fogón que proporcionó la datación de $4930+110$ AP se ubicaba en G3b, a escasos $2 \mathrm{~m}$ de distancia al O-NO del fardo, aún bajo el reparo de la cueva, pero con el techo a mayor altura.

El fardo estaba apoyado a $0,49 \mathrm{~m}$ de profundidad absoluta bajo la cumbre de la pila sedimentaria (nivel " 0 " en ese sector) sin que mediara ninguna estructura de cavado o fosa desde las capas superiores. La ausencia de fosa indicaba que todo el paquete funerario se apoyaba sobre el nivel original de ocupación de la capa $2 b(2)$ y que sobre el fardo fueron arrojados restos de comida y otros vestigios que podrían considerarse "desechos" o "basura". Pero el fardo convivió, por así decirlo, en una ubicación marginal o lateral con las actividades domésticas que ocurrieron en el alero y en el sector de la cueva, que permitía la circulación humana a juzgar por la variedad de artefactos recuperados en el entorno del fogón mencionado (Aschero et al., 1991), y fue sucesivamente cubierto por estos desechos y por la sedimentación normal de la cueva, con abundante aporte eólico favorecido por esta topografía.

\section{El fardo funerario}

El fardo funerario, de aproximadamente $0,80 \mathrm{~m}$ de largo por $0,50 \mathrm{~m}$ de ancho, estaba compuesto por una serie de partes: 1) cobertura externa de cuero; 2 ) envoltorio de cuero interno; 3) cordel; 4) haces de paja; 5) rocas; y 6) feto humano (Fig. 3).

El fardo consistía en dos pieles de camélidos, una usada como cobertura externa (pieza $\mathrm{N}^{\mathrm{o}}$ 1) y otra como envoltorio de los restos óseos de un feto humano (pieza $\mathrm{N}^{\circ}$ 2) (Fig. 4), ambas contenidas en el centro de un "paquete" inten-

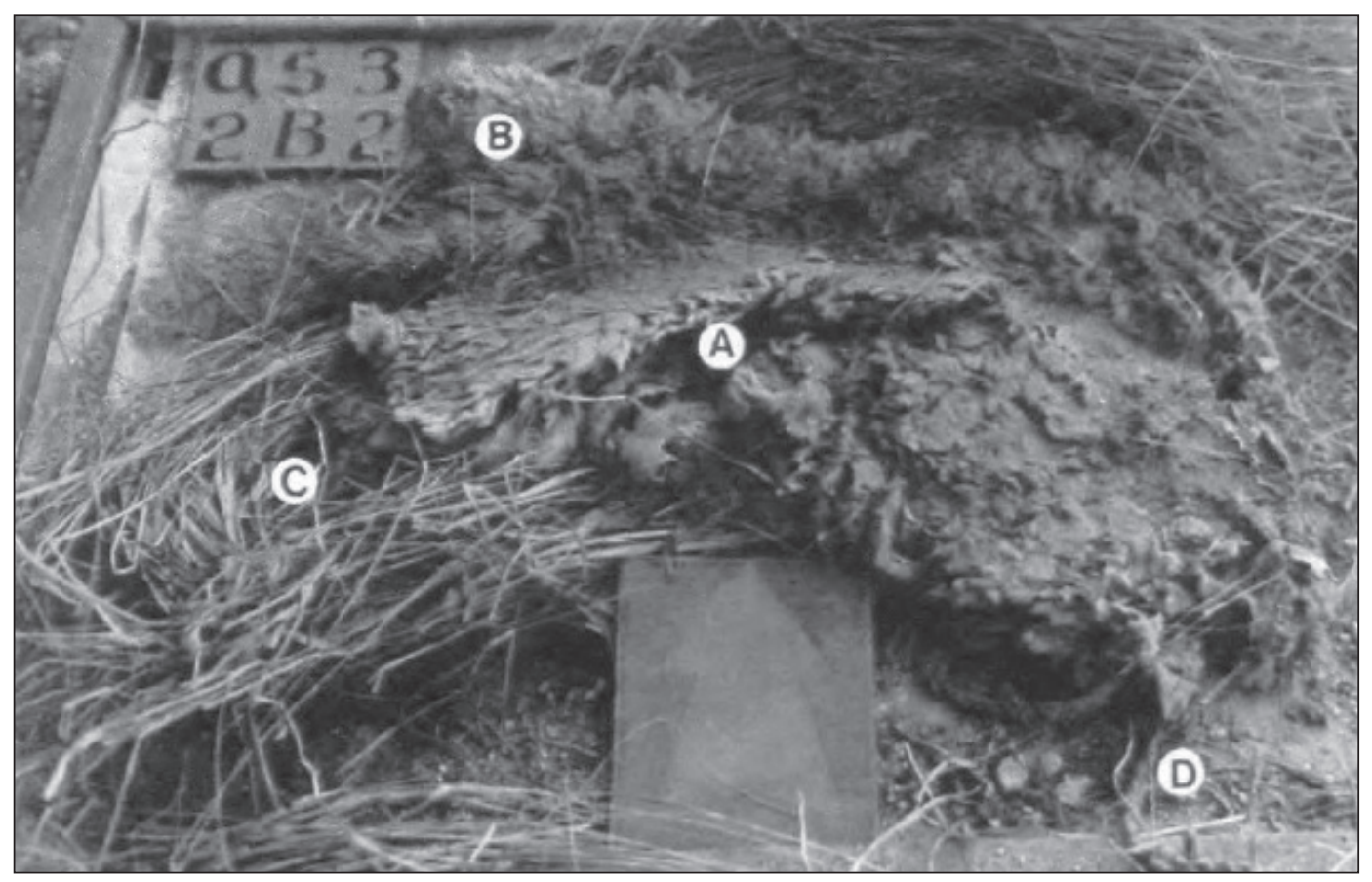

Fig. 3. Imagen del fardo funerario en su lugar de hallazgo. A: Envoltorio de cuero con feto humano en su interior. B: Cobertura de cuero. C: Haces de paja. D. Cordel (modificado de Rodríguez, 1999: 237, Fig.5). 
cional de haces de gramíneas identificadas como Deuyexia eminens (Rodríguez et al., 2003). Por encima del fardo se observaron unas pocas (3) piedras de coloración rojiza (vulcanitas) traídas del exterior del alero, usadas para la demarcación del fardo, y varios clastos de la ignimbrita de caja. La presencia de estos últimos seguramente se debe a desprendimientos posteriores del techo de la cueva. Una de las rocas demarcatorias tenía -en su parte superior- adherencias de excrementos compactados de roedor de capa " 0 ".

El cuero $\mathrm{N}^{0} 1$, externo, presentaba el pelo hacia afuera, al igual que el del envoltorio interno. Ambos cueros corresponden a pieles de camélidos (no identificados) sometidas a procedimientos de curtido o limpieza de la cara interna (carne). El primer cuero mencionado tenía dos orificios laterales por donde pasaba un cordel de lana (torsión $\mathrm{z}$ de dos cabos) que sujetaba y ceñía el envoltorio del segundo cuero con este. Este primer cuero tenía una parte plegada en el centro y una costura de reparación con un hilo de tendón, visible en la cara interna, que empezaba con un nudo y terminaba libre (Figs. 4, 5). En esta parte de la cara interna el cuero se veía manchado y más desgastado, como si hubiera sido usado antes de formar parte del fardo. Este cuero, de $35 \times 25 \mathrm{~cm}$, estaba recortado en la parte más angosta, semejando la forma que tendría una piel recién extraída, con una porción de las patas traseras y el rabo del animal groseramente reproducidos (Fig. 5).

El cuero $\mathrm{N}^{\circ} 2$ (interno) presentaba un marcado grado de deterioro, mayor en la porción en la que apoyaba el cráneo del feto. Cerrado como envoltorio medía 41 x 18 x $5 \mathrm{~cm}$ (Ø promedio) y mostraba cristales de sal en el exterior $\mathrm{y}$, a medida que se lo fue abriendo, también en el interior. En la parte interna, mejor conservada, se observaron restos de pintura roja. En la parte externa y más deteriorada el pelo presentaba una coloración oscura, más adherencias o suciedad y se desprendía fácilmente. En la parte interna, este sector más deteriorado también mostraba horadaciones atribuibles a insectos. El ceñido del cordel en torno a este segundo cuero, que contenía los restos esqueletarios, sugería claramente que el resto del esqueleto no formaba, originalmente, parte del envoltorio.

Los dos cordeles de torsión $\mathrm{Z}$ que envolvían

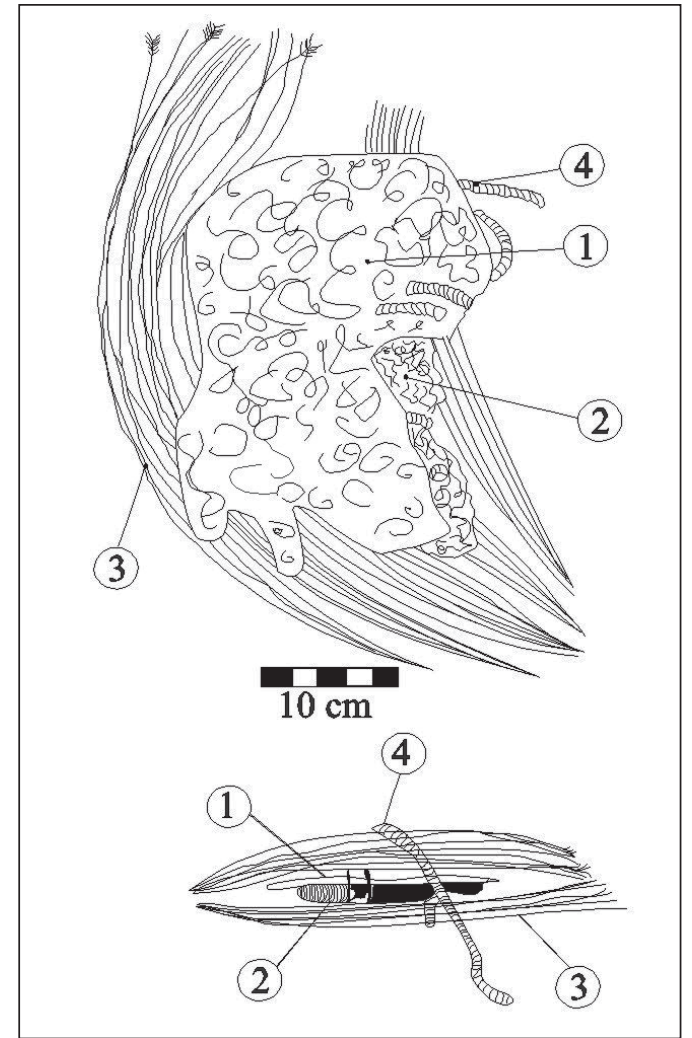

Fig. 4. Representaciones gráficas del fardo funerario. Arriba: vista en planta. Abajo: croquis en vista lateral. 1) Cobertura de cuero externa. 2) Envoltorio de cuero interno. 3) haces de gramíneas. 4) Cordel (Libreta de campo de Carlos A. Aschero, 1988).

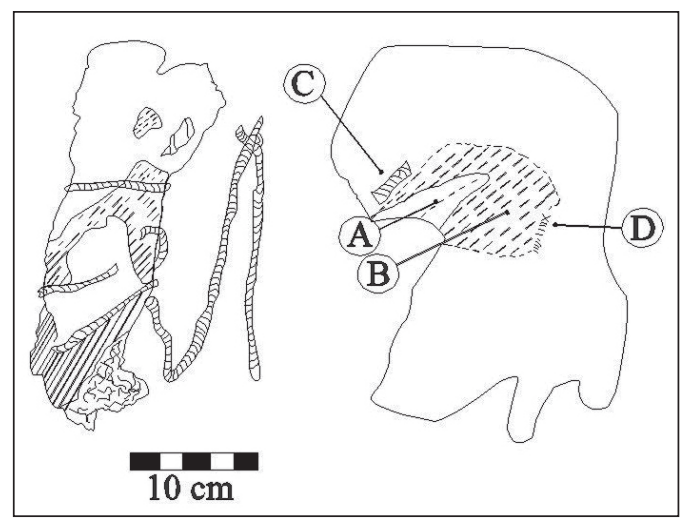

Fig. 5. Representaciones gráficas del fardo funerario. Izquierda: Envoltorio funerario interno. Derecha: Vista del cuero externo desplegado. A) Pliegue. B) Porción desgastada. C) Cordel. D) Costura de reparación (Libreta de campo de Carlos A. Aschero, 1988). 
el fardo eran de fibra de camélido. Uno medía $110 \mathrm{~cm}$ de largo y el otro $43 \mathrm{~cm}$. El diámetro de ambos cordeles era de $5 \mathrm{~mm}$. El cordel más corto se unía mediante un nudo al más largo cerca de uno de sus extremos.

Finalmente, con respecto a la utilización de gramíneas, el fardo fue cubierto, rodeado y apoyado en haces de gramíneas de Deyeuxia eminens var. eminens (Rodríguez et al., 2003). Estas se extrajeron completas, con órganos vegetativos y reproductivos; específicamente, se recuperaron hojas y cañas floríferas con órganos reproductivos (Rodríguez, 1999; Rodríguez et al., 2003).

\section{MATERIAL Y MÉTODOS}

Se realizó un análisis cualitativo de los restos óseos humanos sobre la base de la morfología y del desarrollo de los huesos a través de una inspección macroscópica y con lupa de medianos aumentos. Asimismo, se efectuó un análisis cuantitativo para calcular medidas de abundancia taxonómica y además evaluar variables métricas para la estimación de la edad. Se aclara que solo unos pocos huesos pudieron ser utilizados para determinar la maduración esquelética debido a que la mayoría estaban deteriorados por procesos posdepositacionales.

Se consideraron medidas de abundancia taxonómica (NISP) y relativa (NME, MAU y MAU\%) (Binford, 1984; Lyman, 1994), y el número mínimo de individuos (NMI). El NISP hace referencia al número de especímenes óseos, enteros o fragmentados, pertenecientes a un mismo taxón. En nuestro caso, se analizó un solo taxón, Homo sapiens sapiens, con lo cual el NISP corresponde al número de huesos totales que conforman la muestra bajo estudio. NME es el número mínimo de elementos. Calcula las veces que un mismo elemento óseo está presente en la muestra, independientemente de la lateralidad. Como se trata de un individuo inmaduro, para calcular el NME se tomaron las partes de un mismo elemento óseo como unidad y para el NISP se cuantificó cada una de las partes de un mismo elemento óseo no fusionado. El MAU es la unidad anatómica mínima y se calcula para cada unidad anatómica dividiendo el NME por su frecuencia en el esqueleto completo. El MAU\% expresa en porcentajes los valores del
MAU estandarizados respecto de la unidad anatómica con el MAU más alto (100\%), de acuerdo con la siguiente fórmula: MAU $\%=[(\mathrm{MAU}$ conocidox100)/MAU más alto de la muestra]. Para calcular la integridad esqueletal se tomó como referencia que un individuo inmaduro completo tiene 214 huesos. Para representar el porcentaje de elementos óseos presentes para cada parte del esqueleto se tomaron cuatro rangos porcentuales arbitrarios (0-25\%; 26-50 $\%$; 51-75 \% y 76-100 \%) (González, 2007). El NMI es el número mínimo de individuos identificados por taxón y se calculó a partir del hueso que más representación tuvo en la muestra considerando la lateralidad. Para identificar el deterioro óseo por fricción se siguió la propuesta de Gordon y Buikstra (1981) que evalúa la alteración macroscópica de la superficie cortical y trabecular de cada hueso debida a factores postdepositacionales. Las categorías utilizadas para identificarlo fueron extraídas de Luna et al. (2012), a saber: 1=aspecto de la superficie cortical suave con mínimo o nulo deterioro a nivel macroscópico; 2=superficie cortical suave en gran parte del elemento óseo en sectores acotados, presencia de destrucción parcial cortical y exposición de tejido esponjoso; $3=$ superficie cortical rugosa, áspera y/o agrietada, con grado inicial de erosión y pérdida cortical en sectores de los bordes, y alteración mínima o nula de la trabécula; y $4=$ deterioro masivo de la superficie del hueso con pérdida de tejido y alta exposición de la trabécula ósea. Asimismo, siguiendo a Behrensmeyer (1978) se identificó el grado de meteorización de los elementos óseos.

En la estimación de la edad se utilizaron porciones óseas que se han osificado, lo cual es posible desde el cuarto o quinto mes de gestación (Campillo y Subirá, 2004). A pesar de ello, es difícil estimar si un feto nació a término o si se trata de un individuo de pocas horas o días; debido a esto, es frecuente la terminología perinatal (González Martín, 1998) para los restos óseos desde la semana 24 de gestación hasta los 7 días de vida (Scheuer y Black, 2000). Así, por tratarse de un individuo inmaduro, se utilizaron parámetros específicos, tomando en cuenta la aparición, morfología y fusión de los diferentes centros de osificación del hueso (White y Folkens, 1991; Brothwell, 1993; Buikstra y Ubelaker, 1994; Scheuer y Black, 2000, 2004; 
Rissech, 2007). Además, siguiendo a Scheuer y Black (2000), para la estimación de la edad se evaluaron diversos indicadores morfológicos que permiten considerarlo como perinato: particularmente, en el esqueleto craneal, la presencia del esfenoides separado, la escama del occipital separada -parte lateral y basal-, el hemifrontal dividido y la mandíbula bífida (completa con ausencia de dientes); mientras que en el esqueleto poscraneal se consideró el ilion, el isquion $\mathrm{y}$ el pubis sin fusionar.

Para denominar la categoría etaria se utilizó la propuesta de Scheuer y Black (2000): feto (de la novena semana intrauterina hasta el nacimiento); perinato (de la semana 24 de gestación hasta los 7 días posnatales); neonato (desde el nacimiento hasta los 28 días de nacido); e infante (desde el nacimiento al año de vida). Así, se considera feto a aquel individuo que falleció antes de completar su desarrollo embrionario ( 9 meses de gestación). En la literatura médica la definición de parto prematuro o pretérmino hace referencia a aquellos nacimientos que se producen antes de completar la semana 37 de gestación (Kimberly y Choherty, 2005). A su vez, los nacimientos prematuros pueden clasificarse en diversas categorías: prematuro (nacimiento que se produce entre las 23 y las 37 semanas de gestación); prematuro tardío (nacimiento que se produce entre las semanas 34 y 36 de gestación); prematuro moderado (nacimiento que se produce entre las semanas 32 y 34 de gestación); prematuro extremo (nacimiento que se produce antes de las 32 semanas de gestación); y prematuro muy extremo (antes de las 28 semanas de gestación) (Hübner y Ramírez, 2002).

En la variación de las dimensiones óseas de los huesos se emplearon parámetros propuestos por Fazekas y Kósa (1978) y Scheuer y Black (2000). En el omóplato se midió la longitud total, la anchura y longitud de la espina; en los huesos del coxal, el largo y ancho del ilion, del isquion y el largo del pubis, y la longitud de la primera y segunda costilla izquierda. Asimismo, siguiendo a Scheuer y Black (2000), el cálculo de la estatura, a través de la cuerda de las costillas, fue empleado como un indicador más para la estación de la edad, ya que la pérdida de tejido óseo en las metáfisis de los huesos largos no permitió establecer su longitud. Los datos obtenidos fueron comparados con las tablas con- feccionadas por los autores mencionados arriba. Estos elementos fueron seleccionados por presentar una mayor conservación en relación con otras porciones óseas y porque su dimensión real no se vio afectada, lo cual permitió la aplicación de estos métodos.

La determinación sexual en individuos subadultos se ve dificultada porque el nivel de expresión del dimorfismo sexual es menor que el de individuos adultos (Holcomb y Konisberg, 1995). Si bien en la actualidad las técnicas odontométricas para la determinación del sexo en subadultos son más útiles que las basadas en la morfología ósea y en el futuro la determinación del sexo basada en el ADN antiguo se utilizará de manera más rutinaria, los problemas significativos posiblemente se mantendrán (Mays, 2013). En el subadulto bajo análisis, la determinación del sexo no fue incluida. A futuro se realizarán análisis morfológicos y genéticos con el objetivo de obtener una aproximación al sexo de este individuo.

\section{RESULTADOS}

\section{Análisis bioarqueológico}

EL NMI corresponde a un único individuo. Las porciones óseas identificadas se detallan en la Figura 6. El gráfico no incluye 27 huesos de las manos, 3 vértebras lumbares, 1 fragmento de conducto auditivo interno y 1 fragmento del ala mayor del esfenoides. Debido al tamaño diminuto y al estado de fragmentación de estos, si bien pudo individualizarse anatómicamente cada hueso, no fue posible determinar la lateralidad. Por ello no se incluyen en la Figura 6, aunque estos elementos óseos sí fueron contabilizados en el análisis cuantitativo.

El estado de preservación en general es bueno, con poca presencia de hongos en todos los huesos. Las diáfisis de los huesos largos tienen buena preservación y los extremos proximales presentan pérdida de la capa cortical del hueso, considerando un grado 3 de deterioro óseo. Esta preservación diferencial también se registró en coxal y omóplato, la cual puede ser explicada a partir de los lineamientos de Guy et al. (2007) y Luna et al. (2012). Al analizar el estado de meteorización de acuerdo con Behrensmeyer (1978), se registró un grado 0. 


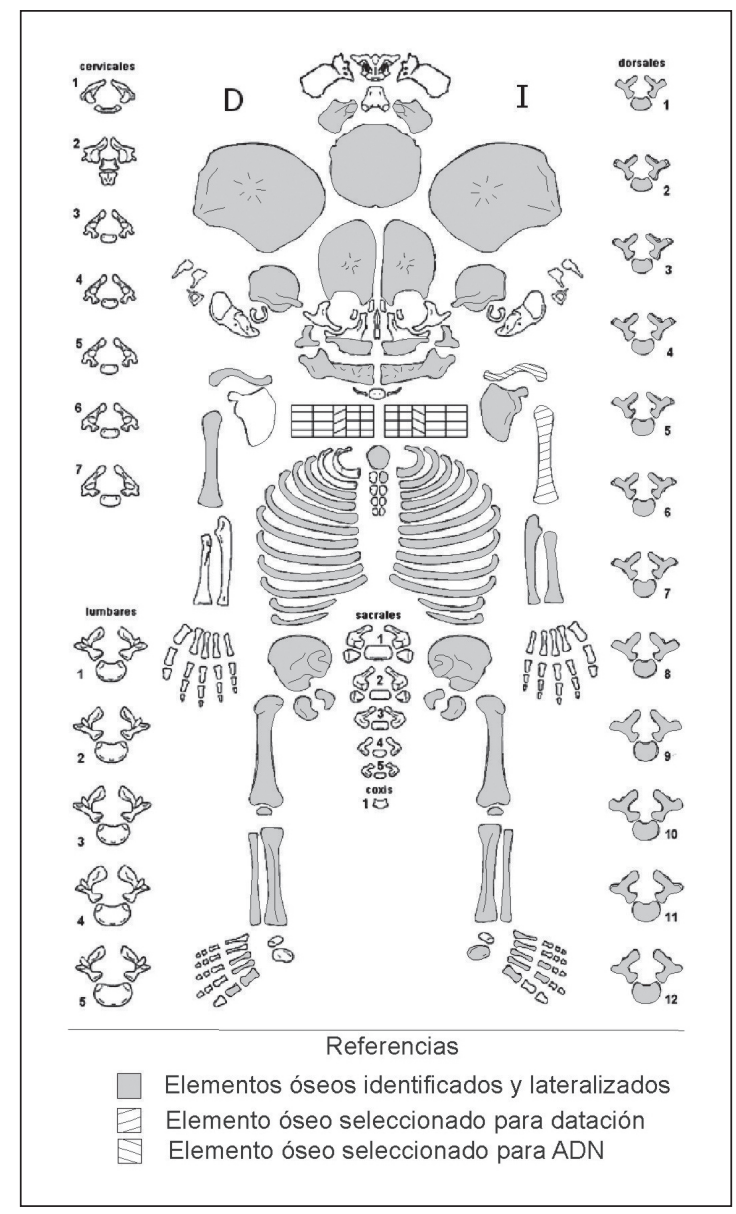

Fig. 6. Elementos óseos identificados y lateralizados.

Como muestra la Figura 6, en el interior del fardo funerario se recuperaron las partes esqueletarias de un único individuo con $\mathrm{N}=139$ huesos del esqueleto, lo que representa una integridad esqueletal del 64,95\%. Esto implica su inclusión en el rango de 51-75\% de representación ósea. Están ausentes el pars basilaris, partes del esfenoides, las 7 vértebras cervicales, 2 vértebras lumbares, la primera y segunda costilla derecha, el omóplato derecho, el radio y cúbito derecho y el calcáneo derecho (Fig. 7). Se seleccionaron para datación el húmero izquierdo y para ADN la clavícula izquierda. Se destaca que los mismos fueron considerados en el análisis cuantitativo (Tabla 1 y 2). Los huesos no lateralizados son un fragmento de conducto auditivo interno, un fragmento de ala mayor del esfenoides y huesos de la mano. Cabe mencionar que un fragmento de huesos indeterminados no fue considerado en el análisis.
En la Tabla 1, los 15 huesos identificados como parte del cráneo son el occipital con el pars lateralis derecho e izquierdo, ambos parietales, frontales, temporales, cigomáticos y maxilares. No pudo determinarse la lateralidad de un ala mayor del esfenoides y de un fragmento de conducto auditivo interno (pars petrosa). Con respecto a las vértebras, están presentes 12 cuerpos vertebrales y 27 paredes vertebrales. De estas últimas, 24 corresponderían a vértebras dorsales y 3 a lumbares indeterminadas. Las manos y los pies están incompletos, con un total de 39 huesos entre ambos, de los cuales 27 piezas corresponden a las manos y 12 a los pies. La determinación de la posición y de la lateralidad (por ejemplo, segundo metacarpo izquierdo o cuarta falange) es muy compleja, puesto que se trata de huesos muy pequeños, de 3 o $5 \mathrm{~mm}$. Por ello, se graficó en la Figura 6 de modo tentativo la po- 


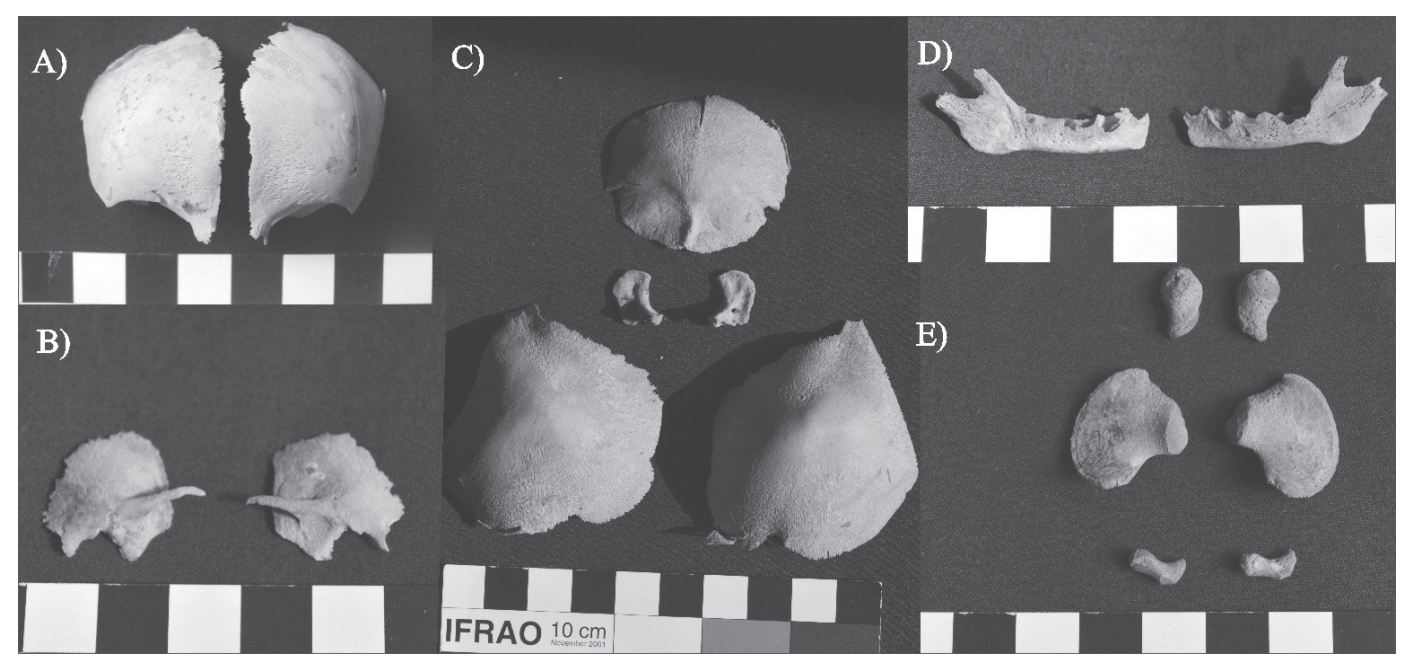

Fig. 7. Imagen de los indicadores morfológicos para la estimación de la edad. A) Hemifrontal dividido. B) Esfenoide separado. C) Escama del occipital separado. D) Mandíbula bífida. E) Ilion, isquion y pubis sin fusionar.

sible ubicación de los metatarsos y falanges de los pies. Para el caso de los huesos de la mano solo se identificó el tipo de hueso (metacarpo y falange) y la cantidad de cada uno (Tablas 1 y 2), pero no su posición, ya que la inmadurez en su desarrollo dificulta la ubicación anatómica individual (García Mancuso, 2008). Por ende, no están representados en la Figura 6.

La edad de gestación fue estimada a través de un análisis cuantitativo basado en mediciones del omóplato, el coxal y las costillas. De acuerdo con los números arrojados por el omóplato y el coxal, se estima una edad de entre 28 y 30 semanas intrauterinas de gestación. La medición de la primera $(16,4 \mathrm{~mm})$ y de la segunda (25,6 mm) costilla izquierda ubica la edad de gestación en 24 a 30 semanas (Fazékas y Kósa, 1978; Scheuer y Black, 2000). La estimación de la estatura a partir de la longitud de la cuerda de las costillas da como resultado una estatura de entre 27 y $35 \mathrm{~cm}$, que correspondería a un feto de entre 5 y 7 meses de gestación; es decir que nació de forma prematura. Así, la edad estimada de muerte del individuo analizado es de $7 \pm 1$ meses de gestación, dado que las mediciones de los huesos en la mayoría de las tablas consideradas (Fazékas y Kósa, 1978; Scheuer y Black, 2000) oscilan entre 28 y 30 semanas de gestación, y puesto que las particularidades en el desarrollo de los huesos son acordes con ello (Tabla 3).

En cuanto a los indicadores morfológicos que permiten considerarlo como perinato, se evaluó particularmente la presencia del esfenoides separado, la escama del occipital (pars lateral y basal) separada; el ilion, el isquion y el pubis fragmentados; el hemifrontal dividido en dos partes y la mandíbula bífida (Scheuer y Black, 2000) (Tabla 4 y Fig. 7).

A partir de los resultados de los análisis cuantitativo y cualitativo se estima una edad que se acercaría más a un feto de 7 meses de gestación que a uno de 6 meses, lo que equivaldría a 28 semanas de gestación. Si estimamos una edad de gestación de alrededor de 28 semanas, podría considerarse como un prematuro extremo (Hübner y Ramírez, 2002).

\section{Dinámica de depositación del feto}

La interpretación de las características de la depositación del feto requiere considerar, por un lado, las condiciones de hallazgo y la preservación del fardo funerario y, por otro lado, el porcentaje de integridad esqueletal. Esto permite proponer un mecanismo en el transporte del fardo.

Del análisis del registro in situ del fardo funerario y su posterior observación en laboratorio se deprende que tanto el envoltorio interno como el externo que lo conformaban no presentan señales que sugieran una rotura ni una reapertura del mismo. Es decir, el fardo actuó como un contenedor cerrado. 
TABLA 1. Valores de las medidas de abundancia taxonómica y relativa de la muestra estudiada

\begin{tabular}{|c|c|c|c|c|}
\hline Elemento óseo & NISP & NME & MAU & MAU\% \\
\hline Cráneo & 15 & 1 & 1 & 100 \\
\hline Mandíbula & 2 & 1 & 1 & 100 \\
\hline Clavícula & 2 & 1 & 0.50 & 50 \\
\hline Vértebras dorsales & 36 & 12 & 1 & 100 \\
\hline Vértebras lumbares & 3 & 3 & 0.60 & 60 \\
\hline Omóplato & 1 & 1 & 0.50 & 50 \\
\hline Húmero & 2 & 1 & 0.50 & 50 \\
\hline Cúbito & 1 & 1 & 0.50 & 50 \\
\hline Radio & 1 & 1 & 0.50 & 50 \\
\hline Metacarpo & 8 & 8 & 0.80 & 80 \\
\hline Falanges & 18 & 18 & 0.32 & 32 \\
\hline Trapezoide & 1 & 1 & 0.50 & 50 \\
\hline Costillas & 22 & 22 & 0.91 & 91 \\
\hline Esternón & 1 & 1 & 1 & 100 \\
\hline Fémur & 2 & 2 & 1 & 100 \\
\hline Coxal & 6 & 2 & 1 & 100 \\
\hline Tibia & 2 & 2 & 1 & 100 \\
\hline Rótula & 2 & 2 & 1 & 100 \\
\hline Peroné & 2 & 2 & 1 & 100 \\
\hline Calcáneo & 1 & 1 & 0.50 & 50 \\
\hline Metatarsos & 8 & 8 & 0.80 & 80 \\
\hline Falanges & 3 & 3 & 0.50 & 50 \\
\hline
\end{tabular}

En negrita se resaltan los valores más altos para cada una de las columnas.

NISP=Número de especímenes identificados, NME= Número mínimo de elementos, MAU=unidad anatómica mínima, $\mathrm{MAU} \%=$ porcentaje de valores de MAU

Esta envoltura contuvo los elementos óseos, evitando que se perdieran, y no interfirió en la integridad esqueletal. Si consideramos que en la excavación de esqueletos inmaduros es común la pérdida de registro de elementos óseos por un inadecuado proceso de extracción durante la ex- cavación y por la eventual falta de conocimientos de anatomía de los operarios (Molero Rodrigo, 2013), en este caso esto no habría ocurrido en virtud de la presencia de los envoltorios. Por otro lado, el envoltorio interior no fue afectado por roturas y los huesos no presentan marcas de 
TABLA 2. Porcentaje de elementos óseos identifica-

$\underline{\text { dos }}$

Integridad esqueletal

Individuo Elementos óseos recuperados Rango \%

$\begin{array}{cccc} & \mathrm{N} & \% & \\ \text { QS3 } & 139 & 64.95 & 51-75\end{array}$

roído, de carnívoros o superficie blanquecina, que indicarían una exposición a la intemperie prolongada. Por esto, el grado de completitud del perinato no es muy elevado, lo que debe ser explicado por otras causas.

La preservación de los elementos óseos es satisfactoria si consideramos que los huesos en desarrollo son más frágiles y menos resistentes a la abrasión y a los agentes químicos que el tejido óseo de un adulto, ya que los huesos inmaduros tienen mayor porcentaje de material orgánico y una distribución irregular de la sustancia mineral (Guy et al., 1997; García Mancuso, 2008). Se observó una preservación diferencial entre las diáfisis y la metáfisis distal y proximal en los huesos largos. En esta última la capa cortical estaba ausente, con el tejido esponjoso expuesto. Esto se debe a que las diáfisis tienen una densidad mineral más alta, lo que favorece su preservación, y la metáfisis es menos densa por tener una mayor proporción de tejido esponjoso, por lo que queda más expuesta al deterioro mecánico (Lyman, 1994; Molero Rodrigo, 2013).

Si bien es necesario considerar la densidad del hueso como condicionante de la preservación diferencial y los procesos tafonómicos (Lyman, 1994), en este caso también debe tenerse en cuenta que los huesos estuvieron aislados del entorno externo y, a pesar de ello, muestran una preservación diferencial. Dadas las características de integridad excepcional del fardo funerario que los contenía, es plausible plantear una depositación inicial del esqueleto antes de ser colocados los restos humanos de manera incompleta dentro de este envoltorio. En dicha disposición inicial bajo sedimento fueron afectados por agentes físicos y mecánicos que alteraron la capa cortical del hueso, lo cual generó un grado 3 de deterioro

TABLA 3. Análisis cuantitativo para la estimación de la edad de gestación

\begin{tabular}{|c|c|c|c|c|}
\hline Elemento óseo & \multicolumn{2}{|c|}{ Variable y valor de medición } & $\begin{array}{l}\text { Edad de } \\
\text { gestación }\end{array}$ & Fuente bibliográfica \\
\hline \multirow{3}{*}{ Escápula izq. (cm) } & Long. Total & 2.27 & \multirow{3}{*}{$22-30$ semanas } & \multirow{14}{*}{$\begin{array}{l}\text { Fazékas y Kósa (1978); } \\
\text { Scheuer y Black (2000) }\end{array}$} \\
\hline & Anchura & 1.97 & & \\
\hline & Long. Espina & 1.78 & & \\
\hline \multirow{2}{*}{ Ilion der. (mm) } & Largo & 20.0 & \multirow{4}{*}{ 26-28 semanas } & \\
\hline & Ancho & 18.8 & & \\
\hline \multirow{2}{*}{ Ilion izq. (mm) } & Largo & 21.0 & & \\
\hline & Ancho & 18.3 & & \\
\hline \multirow{2}{*}{ Isquion der.(mm) } & Largo & 11.4 & \multirow{4}{*}{ 28-32 semanas } & \\
\hline & Ancho & 6.5 & & \\
\hline \multirow{2}{*}{ Isquion izq.(mm) } & Largo & 11.9 & & \\
\hline & Ancho & 6.6 & & \\
\hline \multirow[t]{2}{*}{ Pubis der.(mm) } & Largo & 8.6 & \multirow{3}{*}{ 30-32 semanas } & \\
\hline & & & & \\
\hline Pubis izq.(mm) & Largo & 9.0 & & \\
\hline
\end{tabular}

Long.=longitud, der.=derecha, izq. $=$ izquierda. 
TABLA 4. Indicadores morfológicos para la estimación de la edad observados en los esqueletos (según Scheuer y Black, 2000)

\begin{tabular}{|c|c|c|c|}
\hline \multicolumn{2}{|c|}{ Porción anatómica } & Indicador morfológico & Edad estimada \\
\hline \multirow{11}{*}{ Cráneo } & & $\begin{array}{l}\text { La porción petrosa no tiene fusionado el anillo } \\
\text { timpánico, éste último está ausente }\end{array}$ & menor a 8 ó 9 meses de gestación \\
\hline & & $\begin{array}{l}\text { Su morfología se asemeja más a un feto de } 8 \\
\text { meses que a uno de } 5 \text { meses intrauterinos }\end{array}$ & 8 meses de gestación \\
\hline & Occipital y & La porción petrosa osificada & más de 5 meses de gestación \\
\hline & Esfenoides & $\begin{array}{l}\text { La porción escamosa, basilar y lateral no } \\
\text { fusionadas }\end{array}$ & $\begin{array}{l}\text { al momento del nacimiento aún } \\
\text { están sueltas }\end{array}$ \\
\hline & Frontal & El ala mayor del esfenoides se presenta suelta & menor a 9 meses de edad \\
\hline & & Dividido en dos partes por la sutura metópica & perinato hasta los dos años de vida \\
\hline & Parietal & Con la fontanela sagital & 6 meses de gestación \\
\hline & Cigomático & Osificado y con adopción de la morfología adulta & 6 meses de gestación \\
\hline & Maxilar & Las criptas para los dientes deciduos completas & mayor a 18 semanas de gestación \\
\hline & Mandíbula & $\begin{array}{c}\text { Presenta los gérmenes dentales los cuales inician } \\
\text { su desarrollo hacia la semana 14-16 }\end{array}$ & mayor a 16 semanas de gestación \\
\hline & & La mandíbula sin fusionar & menor de 10 meses de edad \\
\hline \multirow{3}{*}{$\begin{array}{l}\text { Post- } \\
\text { cráneo }\end{array}$} & Clavícula & $\begin{array}{l}\text { Con forma de } \mathrm{S} \text { y adopción de la morfología } \\
\text { adulta }\end{array}$ & mayor de 10 semanas de gestación. \\
\hline & Omóplato & $\begin{array}{c}\text { Presenta la fosa glenoidea y el acromio. El } \\
\text { proceso coracoideo ausente, éste comienza a } \\
\text { osificarse recién al año de vida }\end{array}$ & 12 semanas de gestación \\
\hline & Coxal & El isquion está separado & entre 6 y 8 meses de gestación \\
\hline
\end{tabular}

óseo por fricción con el sedimento. Esto bien puede relacionarse con las condiciones del sedimento donde estuvieron previamente depositados. Por ejemplo, los sedimentos con PH ácido disminuyen la probabilidad de conservación y alteran los huesos (Brothwell, 1993; Molero Rodrigo, 2013). Esta es una manera válida de explicar esa preservación diferencial sin dejar de considerar la naturaleza del hueso inmaduro, pero para una mayor consistencia del planteo, es necesario confrontar estos indicios con otros factores que a continuación detallaremos, relacionados con la integridad esqueletal del conjunto óseo.

La integridad esqueletal es del 64,95\%, es decir que del $100 \%$ de representación ósea solo presenta un rango de entre el 51 y el $75 \%$ (Ta- bla 2). Como la conservación de los envoltorios interno y externo indica que los huesos ausentes no se perdieron por roturas y que esto permitió, a su vez, que el proceso de excavación no alterara el registro óseo; y como los elementos óseos no presentan huellas de acción de roedores o carnívoros que expliquen una ausencia debido a su perturbación, sostenemos que el fardo hallado en Quebrada Seca 3 habría ingresado al alero con un perinato incompleto.

Por un lado, consideramos que, al extraerse el perinato de su lugar de depositación inicial, quedaron allí los huesos no hallados dentro del fardo. Entre ellos, piezas de diminuto tamaño, como vértebras y los huesos de pie y mano. En referencia a esto último, la literatura bioarqueológica da cuenta de que este tipo de huesos 
tienen una escasa supervivencia al manipularse los esqueletos (Waldron, 1994). Por otra parte, es importante destacar la falta de articulación ósea dentro del fardo, es decir que todos los huesos estaban completamente desarticulados sin conexiones anatómicas entre ellos. Esto sería consecuencia directa de la manipulación antrópica del esqueleto e indica que el fardo no fue usado para la depositación inicial del cuerpo, sino que se lo utilizó en la depositación secundaria, porque, de ser el fardo el primer y único contendedor del perinato, serían esperables dichas conexiones anatómicas o, a lo sumo, con ligeros desplazamientos, ya que el fardo funerario actuaría como un "efecto pared", es decir, como un límite que encierra los huesos, evita movimientos que, de otra forma, serían esperables y da persistencia a relaciones anatómicas muy inestables creando un espacio vacío delineado que evitaría el contacto directo entre el cuerpo y el sedimento (Roksandic 2002). Por otro lado, dentro del fardo se halló escasa presencia de fauna cadavérica y nulos tejidos blandos correspondientes a grasa, piel, músculo, vísceras y órganos internos. De haberse descompuesto el cuerpo dentro del fardo, deberían estar presentes, lo que indica que el proceso de putrefacción del cuerpo se dio en otro lugar. Esto lleva a proponer una desarticulación que pudo iniciarse al traspasar el cuerpo ya esqueletizado al fardo funerario donde fue colocado el individuo, ya que no hay marcas de artefactos cortantes que indiquen un desmembramiento de los huesos. Posiblemente, dicho traspaso, desde su localización inicial al fardo, fue lo suficientemente rápido como para no meteorizar la superficie de los elementos óseos por contacto prolongado con la atmósfera, lo cual se mantuvo a través del tiempo debido a la envoltura del fardo funerario que favoreció la buena preservación del esqueleto. Además, dadas las condiciones climáticas de la Puna meridional, presentes y pasadas, caracterizadas por una extrema aridez, y a una altitud superior a los 3500 msnm, sería esperable que, si el fardo hubiera actuado como único contenedor del cuerpo, el mismo se momificara naturalmente como fue el caso del neonato de PP11 localizado sobre una oquedad natural (Aschero et al., 1999) o la momia contenida en un envoltorio del sitio PP4 (Aschero, 2007).

\section{DISCUSIÓN Y CONCLUSIONES}

La información obtenida a través del análisis contextual y bioarqueológico no permite asegurar cuál fue la causa de muerte del perinato, aunque es factible sugerir, de modo hipotético, dos alternativas. Somos conscientes de la dificultad de precisar las causas del óbito fetal en muestras arqueológicas, si se considera que, incluso en la actualidad, bajo condiciones obstétricas adecuadas, no siempre se las puede determinar (Vogelmann et al., 2008).

La primera alternativa (A) es que el perinato analizado podría corresponder a un feto nacido prematuramente; es decir, antes de las 37 semanas de gestación (Marlow et al., 2005), cuando los órganos aún no están completamente desarrollados. En caso de haber nacido con vida, dada su corta edad gestacional, la inmadurez de los alveolos pulmonares debida al déficit de la sustancia surfactante provocaría una muerte por membrana hialina (González Armengod y Omaña Alonso, 2006) que, junto con la inmadurez a nivel cerebral, haría improbable la supervivencia extrauterina (Gusi y Muriel, 2008). En la actualidad, al prematuro se le aplica surfactante para reducir la morbimortalidad (González Armengod y Omaña Alonso, 2006), pero en la prehistoria e incluso en momentos históricos relativamente recientes esta fue una causa de muerte ineludible inmediatamente después del nacimiento.

La segunda alternativa (B) es que el óbito fetal haya sido producto de una muerte fetal intrauterina, es decir, una muerte acaecida durante la gestación, a partir de las 20 semanas y hasta antes del parto o la expulsión del feto (Vogelmann et al., 2008). Aunque en la actualidad, en un número significativo de pacientes, el parto comienza de manera espontánea en las semanas siguientes a la muerte del feto, en algunos casos esto no sucede (falta de dilatación cervical y contracciones intrauterinas) y se induce el parto con medicamentos en el segundo trimestre de embarazo (entre las 13 y 25 semanas de gestación), porque no es fácil expulsar el feto y puede ocasionarle complicaciones a la madre (Reyna et al., 2004/05). Considerando estos datos, en casos arqueológicos una muerte fetal intrauterina por complicaciones durante el embarazo llevaría indudablemente a la muerte de la madre. Justamente, en contextos arqueológicos se han 
recuperado individuos localizados en la cavidad abdominal con edades de gestación de entre 22 y 32 semanas que sugieren una muerte materno-infantil durante la gestación (Bienes Calvo, 2006; Rascón et al., 2007). De acuerdo con De Miguel Ibañez (2010: 143), “... se pueden barajar causas relacionadas con el embarazo, preferentemente cuando la edad fetal es menor de 37 semanas, y un origen vinculado con el parto y sus posibles distocias, cuando los tamaños corresponden con fetos a término (>37 semanas). Siempre con dudas razonables, ya que no es preceptiva la causa obstétrica en estos fallecimientos". En relación con esto, no es lo mismo que un individuo nazca muerto o fallezca poco después, ya que, en caso de haber sido alimentado durante sus pocas horas de vida, habrá comenzado a desarrollar la flora intestinal y la descomposición del cuerpo empezaría de adentro hacia fuera, lo que repercutiría en su preservación y, en caso de nacer muerto, la descomposición se iniciaría de afuera hacia adentro (González Martín, 1999; Molero Rodrigo, 2013).

En función de lo mencionado, si bien no contamos con suficientes evidencias que avalen estas hipótesis, consideramos más viable que la causa de la conclusión del embarazo sea la posibilidad (A). Si tomamos en cuenta la buena preservación del esqueleto, esto sería acorde con lo mencionado por González Martín (1999) en caso de nacer muerto y con la alta mortalidad infantil en sociedades cazadorasrecolectoras.

Por otro lado, entendemos que es complejo deducir si se trata de un entierro secundario o primario. A nuestro juicio la información disponible permite sustentar la idea de que se trata de un depósito funerario secundario, con desarticulación ósea, preparación del fardo y traslado del mismo. Al respecto, se infiere que entre la depositación del esqueleto completo y su hallazgo en el abrigo rocoso medió una alteración antrópica en la cual se manipularon los elementos óseos (incluyendo sustracción de partes), que modificó su estado original. De esta forma, se está en presencia de las dos etapas que caracterizan a los entierros secundarios: una primera etapa en la que el cuerpo es enterrado durante un lapso determinado de tiempo, y otra subsiguiente en la que es exhumado, por lo general para ser enterrado nuevamente $\mathrm{y}$, en este caso, depositado en el fardo. En el caso tratado, esto implicó prácticas de desarticulación que no dejaron marcas evidentes a nivel óseo, debido a la manipulación del cuerpo una vez esqueletizado para su relocalización. La manipulación del esqueleto, aunque no haya implicado descarne, indicaría una preparación y acondicionamiento del fardo funerario (recorte de los cueros, colocación de pintura roja sobre el envoltorio interno, atadura con un cordel, búsqueda de los haces de paja, etc.) y del individuo (desarticulación durante la manipulación se refiere a cuando fue colocado en el fardo). Siguiendo a White y Folkens (2005), las inhumaciones secundarias se caracterizan por colocar las unidades anatómicas de manera diferente respecto de su ubicación original. En este sentido, Schoreder (2001) sostiene que este tipo de entierros se caracterizan por la manipulación intencional del cuerpo. Los ejemplos clásicos son los paquetes mortuorios, las acumulaciones óseas o los cráneos aislados, pero situaciones como la expuesta se encuadran en dichas definiciones. En general, los ejemplos enunciados involucran la selección de ciertas partes para ser integradas al entierro secundario, mientras que, en el caso analizado, en cambio, se retiraron partes específicas. Se considera que esto no invalida la adscripción del entierro estudiado como secundario; sino que apunta, más bien, a una variabilidad manifiesta.

Ubelaker (1978) da cuenta de otra característica importante en los entierros secundarios, ya que se refiere a estos como colecciones de huesos no articulados que implican un complicado método de tratamiento mortuorio. Si bien en este caso no se trata de una colección de huesos propiamente dicha, la ausencia de articulación entre los huesos, la selección de partes y la evidente complejidad del paquete funerario son elementos a tener en cuenta en ese sentido.

Ahora bien, para Wallthall (1999), en los entierros primarios los cadáveres son dispuestos completamente articulados en la sepultura, sin evidencias de procesamiento o de haber sido perturbados desde su depositación. Claramente, el caso analizado se diferencia por lo anteriormente expuesto.

En suma, al evaluar los indicadores mencionados y tomando en consideración la modalidad de entierro en el área puneña, es factible atribuir este caso a un depósito secundario. 
Con respecto a la posibilidad del transporte del esqueleto, las características del hallazgo nos permiten reflexionar en este sentido. Entendemos que las particularidades del fardo, con envoltorios de cuero atados con un cordel anudado y, a su vez, amarrados a haces de paja permiten sugerir un acondicionamiento para su traslado, en función del armado de un "paquete". Se plantea, en suma, la posibilidad del transporte del fardo funerario desde otro lugar para tener como destino definitivo el depósito donde fue encontrado, independientemente de la distancia entre el último depósito y el anterior. Es decir, una relocalización del difunto, ya sea dentro del mismo sitio o su transporte hacia otra localización: el reparo rocoso en cuestión.

El transporte de partes de cuerpos es una práctica recurrente entre los cazadores-recolectores holocénicos de los Andes Centro-Sur (Aschero 1979, 1984; Santoro et al., 2005; Martínez, 2013), aunque ciertamente limitada en número, por lo que el caso estudiado aporta información relevante, ya que involucra la presencia de un fardo funerario y la ausencia de partes humanas en él.

Es importante mencionar que el fardo funerario dentro del sector cueva de QS3 se ubicaba en una posición periférica, en un espacio restringido en el que la altura del techo del alero no permite pararse sobre el lugar de ubicación del fardo, y en el cual no se halló un pozo o fosa, sino que la depositación del fardo fue realizada sobre la superficie del piso de ocupación. Sobre el fardo se encontraron restos de fauna, lo que permite considerar que en el espacio circundante continuaron desarrollándose actividades cotidianas. Así, mientras el alero fue usado para depositar el fardo funerario, contemporáneamente y después del entierro también se desarrollaron actividades domésticas. Esto permite pensar que las esferas de la vida y la muerte estuvieron compartidas dentro de un mismo espacio, como también lo sugiere el hecho de transportar consigo al difunto, lo que lleva a reforzar el rol de ancestro que los difuntos -y también los fetos y neonatos- cumplen en la configuración de la vida de los vivos (Bastien, 1978; Parker Pearson, 2000; entre otros), ya sea en forma de culto a los ancestros (Nielsen, 2010; Aschero, 2010) o bien para la validación de las genealogías (Montt-Schroeder, 2014).
En el caso Chinchorro de la costa norte de Chile, la "preparación complicada" en las momias de infantes y el uso de partes esqueletarias de fetos en la preparación de figurillas, que acompañan las inhumaciones directas de adultos, es un eslabón más -con cronologías semejantes (Standen et al., 2014)- para reconocer estas prácticas entre los cazadores-recolectores de los Andes Centro-Sur. Este uso de partes humanas -como reliquias de ancestros o como representación de genealogías-, que siguen diferentes derroteros, junto con los lugares en que aparecen depositadas -micro-ambientes con alta concentración de recursos- impulsan a pensar que cumplen con la función social de "marcar" estos sitios en el reclamo de derechos de larga data sobre lugares y recursos (Aschero, 2007).

El tipo de depósito y los restos fetales analizados contribuyen al estudio de la variabilidad de las prácticas funerarias y de la dinámica de tratamiento de las inhumaciones de estos cazadores-recolectores en proceso de cambio. La complejidad de la práctica mortuoria es notable en relación con el importante esfuerzo invertido en la preparación del fardo funerario y en la manipulación de los restos humanos, y permite observar que los fetos y los infantes tenían un rol de importancia dentro de la vida de estos grupos humanos, ya que seguían mediando en las relaciones sociales, formando parte del entramado de su sociedad.

\section{AGRADECIMIENTOS}

A los evaluadores del manuscrito por sus oportunos comentarios que mejoraron sensiblemente el trabajo. Nuestro agradecimiento a C. Aranda por sus sugerencias en el análisis bioarqueológico y a N. Flegenheimer y a Lizzie Pintar por su inestimable ayuda. Este trabajo se desarrolló en el marco de los Proyectos PIP 464 y PIUNT G503 dirigidos por C. Aschero y PICT 1703 dirigido por S. Hocsman.

\section{LITERATURA CITADA}

Aschero CA. 1979. Un asentamiento acerámico en la Quebrada de Inca Cueva (Jujuy). Informe preliminar sobre el sitio Inca Cueva 4. En: Precirculados de las Primeras Jornadas de Arqueología del NOA. Antiquitas (1): 159183. Universidad del Salvador. Buenos Aires. 
Aschero CA. 1984. El sitio ICC-4: un asentamiento precerámico en la quebrada de Inca Cueva (Jujuy, Argentina). Estudios Atacameños 7:62-72.

Aschero CA. 1988. Arqueología precerámica de Antofagasta de la Sierra. Quebrada Seca: una localidad de asentamiento. Informe al CONICET. Carrera del Investigador Científico. Periodo 1986/87. Ms. en archivo. Biblioteca del Instituto de Arqueología y Museo, Facultad de Ciencias Naturales e Instituto Miguel Lillo, UNT. San Miguel de Tucumán, Tucumán.

Aschero CA. 2007. Íconos, huancas y complejidad en la Puna sur argentina. En: Nielsen A, Rivolta M, Seldes V, Vazquez M y Mercolli P, compiladores. Procesos sociales prehispánicos en el sur andino: la vivienda, la comunidad y el territorio. Tomo II. Córdoba: Editorial Brujas. p. 259-290.

Aschero CA. 2010. Arqueología de Puna y Patagonia Centro-Meridional: Comentarios generales y aporte al estudio de los cazadores-recolectores puneños en los proyectos dirigidos desde el IAM (1991-2009). En: Arenas P, Aschero CA, Taboada C, editores. Rastros en el camino. San Miguel de Tucumán: EDUNT . p. 257-293.

Aschero CA, Elkin D, Pintar E. 1991. Aprovechamiento de recursos faunísticos y producción lítica en el precerámico tardío. Un caso de estudio: Quebrada Seca 3 (Puna Meridional Argentina). En: Actas XII Congreso Nacional de Arqueología Chilena 2, p. 101-114. Santiago de Chile.

Aschero CA, Zurita R, Colaneri MG y Toselli A. 1999. El bebé de la Peña. En: Actas del XIII Congreso Nacional de Arqueología Argentina, Tomo II: 329-338. Facultad de Filosofía y Humanidades, Córdoba.

Aschero, CA, Hocsman S. 2011. Arqueología de las ocupaciones cazadoras-recolectoras de fines del Holoceno Medio de Antofagasta de la Sierra (Puna Meridional Argentina). Chungara 43(1):393-411. doi:10.4067/S071773562011000300005

Aschero CA, Manzi L, Gómez G. 1993-94. Producción lítica y uso del espacio en el nivel 2b4 de Quebrada Seca 3. Relaciones de la Sociedad Argentina de Antropología XIX:191-214

Bastien JW. 1978. Mountain of the condor. Metaphor and ritual in an Andean ayllu. New York: West Publishing Co.

Behrensmeyer AK. 1978. Taphonomic and ecological information from bone weathering. Paleobiology 4 (2):150162.

Bienes Calvo JJ. 2006. La necrópolis islámica de Herrerías. Revista del Centro de Estudios Merindad de Tudela 14:41-61.

Binford LR.1984. Faunal remains from Klasies River Mouth. Orlando: Academic Press.

Brothwell DR. 1993. Desenterrando huesos. Excavación, tratamiento y estudio de restos del esqueleto humano. México DF: Fondo de Cultura Económica.

Buikstra J, Ubelaker DH. 1994. Standards for data collection from human skeletal remains. Fayetteville: Arkansas Archeological Survey Research Series $N^{\circ} 44$.

Campillo D, Subirá E. 2004. Antropología física para arqueólogos. Barcelona: Ariel Prehistoria.

De Miguel Ibañez MP. 2010. Una visión de la infancia desde la osteoarqueología: de la Prehistoria reciente a la Edad Media. Complutum 21(2):135-154.

Fazekas IG, Kósa F. 1978. Forensic fetal osteology. Budapest: Akadémiai Kiadó.

García Mancuso R. 2008. Preservación de restos óseos humanos. Análisis de una muestra fetal contemporáneo. Zaranda Ideas 4:1-12.

González ME. 2007. Estudios de interés tafonómico en los restos óseos humanos de Laguna Tres Reyes 1 (Partido de Adolfo Gonzales Chaves, provincia de Buenos Aires). Intersecciones Antropol (8):215-233.

González Armengod C, Omaña Alonso MF. 2006. Síndrome de distrés respiratorio neonatal o enfermedad de membrana hialina. Bol Pediatr 46 (supl 1):160-165.

González Martín A. 1998. El babel terminológico: ¿Neonatos, precoces, fetos, mortinatos, a término o muertos al nacimiento? Boletín de la Sociedad Española de Paleopatología 19:4-6.

González Martín A. 1999. Infancia y adolescencia en la Murcia musulmana. Estudio de restos óseos. Tesis doctoral. Facultad de Ciencias. Universidad Autónoma de Madrid.

Gordon C, Buikstra J. 1981. Soil ph, bone preservation, and sampling bias at mortuary sites. American Antiquity 46(3):566-571. doi:10.2307/280601

Guy HG, Masset C, Baudl AC. 1997. Infant taphonomy. Int J Osteoarchaeol 7:221-229. doi:10.1002/(SICI)10991212(199705)7:3<221::AID-OA338>3.0.CO;2-Z

Gusi F, Muriel S. 2008. Panorama actual de las investigaciones de las inhumaciones protohistóricas del sudoeste mediterráneo europeo. En: Gusi F, Muriel S, Ólaria C, coordinadores. Nasciturus, infans, puerulus. Vobis mater terra. La muerte en la Infancia. Castellón: SIAP Servei d'Investigacions Arqueològiques i Prehistòriques. p 257-329.

Holcomb SMC, Konigsberg LW. 1995. Statistical study of sexual dimorphism in the human fetal sciatic notch. Am J Phys Anthropol 97: 113-125. doi:10.1002/ ajpa.1330970204

Hübner ME, Ramírez R. 2002. Sobrevida, viabilidad y pronóstico del prematuro. Rev Méd Chile 130(8):931-938. doi:10.4067/S0034-98872002000800015

Kimberly GL, Cloherty JP. 2005. Identificación del recién nacido de alto riesgo y valoración de la edad gestacional. Prematuridad, hipermadurez, peso elevado y bajo peso para su edad gestacional. En: Cloherty JP, Eichenwald EC, Stark AR, editores. Manual de cuidados neonatales. Barcelona: Masson. p.50-66.

Luna L, Aranda C. 2005. Evaluación de marcadores sexuales de individuos subadultos procedentes del sitio Chenque I (Parque Nacional Lihuél Calel, provincia de La Pampa, República Argentina). Rev Esp Antrop Fís 25:25-40.

Luna LH, Aranda C, García Gurieb S, Kullock T, Salvarredy A, Pappalardo R, Miranda P y Noriega H. 2012. Factores de preservación diferencial en restos óseos humanos contemporáneos de la "Colección Chacarita" (Ciudad Autónoma de Buenos Aires). Rev Arg Antrop Biol 14(2):53-67.

Lyman RL. 1994. Vertebrate taphonomy. Manuals in Archaeology. Cambridge: University Press. doi:10.1017/ CBO9781139878302

Manzi LM. 1994. Distribución de restos arqueofaunísticos en el nivel de ocupación $2 b(2)$ del sitio Quebrada Seca 3 (Catamarca, Argentina). Hombre y desierto 8:63-98.

Manzi LM. 2006. Estrategias y formas de uso del espacio en poblaciones cazadoras recolectoras de la Puna meridional argentina. BAR International Series 1465. Oxford: Archaeopress.

Marlow N, Wolke D, Bracewell M, Samara M. 2005. Neurologic and developmental disability at six years of age after extremely preterm birth. N Engl J Med 352:9-19. doi:10.1056/NEJMoa041367

Martínez JG. 2013. Contributions to the knowledge of natural history and archaeology of hunter-gatherers of Antofagasta de la Sierra (southern Argentinian puna): the case of Peñas de las Trampas 1.1. En: Pintar EL, editora. Hunter-gatherers from a high-altitude desert. People of 
the Salt Puna (northwest Argentina). BAR International Series. Oxford: Archaeopress. p. 1-23.

Mays S. 2013. A Discussion of some recent methodological developments in the osteoarchaeology of childhood. Childhood in the Past 1(6):4-21. doi:10.1179/17585716 13Z.0000000002

Molero Rodrigo I. 2013. Reflexiones sobre la representación ósea de individuos infantiles en contextos arqueológicos: aportaciones y limitaciones metodológicas. El futuro del Pasado 4:87-102.

Montt-Schroeder II. 2014. Representación humana en Chinchorro: Un estudio arqueológico-visual de momias, estatuillas y figurillas (ca. 7000-3250 AP, Arcaico Medio, Arcaico tardío y Formativo, Costa Norte de Chile). Tesis Doctoral. Universidad Católica del Norte-Universidad de Tarapacá.

Nielsen AE. 2010. Celebrando con los antepasados. Arqueología del Espacio Público en Los Amarillos, Quebrada de Humahuaca, Jujuy, Argentina. Buenos Aires: Mallku Ediciones.

Parker Pearson MP. 2000. The archaeology of death and burial. Texas: A\&M University Press.

Rascón J, Cambra-Moo O, González A. 2007. A multidisciplinary approach reveals an extraordinary double inhumation in the osteoarchaeological record. Journal of Taphonomy 1(2):91-101.

Rissech C, Malgosa A. 2007. Pubis growth study. Applicability in sexual and age diagnostic. Forensic Sci Int 173(23):137-145. doi:10.1016/j.forsciint.2007.02.022

Rodríguez MF. 1999. Plant species (Poaceae, Asteraceae, Fabaceae and Solanaceae) at an archaeological site in the southern Argentine Puna. Journal of Ethnobiology 19(2):228-247.

Rodríguez MF, Rúgolo de Agrasar Z, Aschero C. 2003. El género Deyeuxia (poaceae, agrostideae) en sitios arqueológicos de la Puna Meridional Argentina, provincia de Catamarca. Chungara 35(1):51-72. doi:10.4067/ s0717-73562003000100004
Roksandic M. 2002. Position of skeletal remains as key to understanding mortuary behavior. En: Haglund, WD, Sorg MH, editors. Advances in forensic taphonomy. Method, theory and archaeological perspectives. Boca Raton, London: CRC Press. p 95-113.

Santoro C, Standen V, Arriaza B, Dillehay T. 2005. Andean archaic funerary pattern or postdepositional alteration? The Patapatane burial in the highlands of South Central Andes. Lat Am Antiq 16:329-346. doi: $10.2307 / 30042497$

Reyna-Villasmil E, Guerra-Velásquez M, Torres-Montilla M, Reyna-Villasmil N, Mejia-Montilla J. 2004/05. Misoprostol oral u Oxitocina para la expulsión del feto muerto intrauterino en el segundo trimestre. MedULA 13:29-32.

Scheuer JL, Black S. 2000. Developmental juvenile osteology. New York: Academic Press.

Scheuer JL, Black SM. 2004. The juvenile skeleton. London: Elsevier.

Schroeder S. 2001. Secondary disposal of the dead: crosscultural codes. World Cultures 12(1):77-93.

Standen VG, Arriaza B, Santoro CM, Santos M. 2014. Chinchorro mortuary practices on infants. Lat Am Antiq 25(3): 300-321. doi:10.7183/1045-6635.25.3.300

Ubelaker D. 1978. Human skeletal remains. Excavation, analysis. Washington: Taraxacum.

Vogelmann RA, Sánchez JE, Sartori MF, Speciale JD. 2008. Muerte fetal intrauterina. Revista de Posgrado de la VI Cátedra de Medicina 188:10-17.

Waldron T. 1994. Counting the dead. The epidemiology of skeletal populations. Chichester: John Wiley and Sons.

Wallthall JA. 1999. Mortuary behavior and early Holocene land use in the North American continent. North American Archeologist 1:51-57.

White T, Folkens PA. 1991. Human osteology. San Francisco: Academic Press.

White T, Folkens PA. 2005. The human bone manual. London: Elsevier Academic Press. 